\title{
Perancangan Flowmeter Ultrasonik untuk Mengukur Debit Air Pada Pipa
}

\author{
Hidayahtullah Abdi Robhani*1, Abdul Rouf ${ }^{2}$. \\ ${ }^{1}$ Prodi Elektronika dan Instrumentasi, DIKE, FMIPA, UGM, Yogyakarta, Indonesia \\ ${ }^{2}$ Departemen Ilmu Komputer dan Elektronika, FMIPA UGM, Yogyakarta, Indonesia \\ e-mail: *² abdi.robhani@gmail.com, ${ }^{2}$ rouf@ugm.ac.id
}

\begin{abstract}
Abstrak
Pengukuran debit air dengan menggunakan sifat gelombang ultrasonik menjamin kestabilan profil airan air yang terukur karena sifatnya yang non-intrusif. Pada penelitian ini, telah dirancang sebuah alat pengukur debit air dengan memanfaatkan sifat gelombang ultrasonik untuk mengetahui kecepatannya. Alat dirancang dengan menggunakan dua pasang transmitter dan receiver ultrasonik pada posisi upstream dan downstream terhadap arah aliran air. Gelombang ultrasonik $40 \mathrm{kHz}$ dibangkitkan dengan modul pembangkit pulsa sinusoidal AD9850 DDS. Pengolah data sensor menggunakan sebuah modul mikrokontroler Arduino Due dengan menghitung perbedaan waktu tempuh gelombang ultrasonik yang terukur.

Pengukuran dilakukan pada pipa berdiameter $57 \mathrm{~mm}$ dengan kecepatan aliran divariasikan menggunakan bukaan keran sebesar 25\%, 50\%, 75\%, dan 100\%. Hasil pengukuran menunjukkan nilai perhitungan debit air terendah sebesar $4,4218 \times 10^{-4} \mathrm{~m}^{3} / \mathrm{s} \mathrm{pada}$ bukaan keran $25 \%$ dan debit tertinggi sebesar $2,1535 \times 10^{-3} \mathrm{~m}^{3} / \mathrm{s}$ pada bukaan keran $100 \%$ dengan nilai koefisien korelasi dan koefisien determinasi pada bukaan keran 25\%, 50\%, 75\% dan 100\% secara berturut-turut sebesar 0,9715, 0,9669, 0,9604 dan 0,9647 serta 94,37\%, 93,49\%, 92,24\%, dan 93,07\%.
\end{abstract}

Kata kunci-flowmeter ultrasonik, waktu tempuh, regresi linear, koefisien determinasi

\section{Abstract}

Measurement of water discharge using ultrasonic wave properties ensures the stability of measured water profile because of its non-intrusive nature. In this study, a water discharge measuring device has been developed by utilizing ultrasonic wave properties to determine its speed. The device is designed using two pairs of ultrasonic transmitters and receivers at upstream and downstream positions toward the direction of the water flow. $40 \mathrm{kHz}$ ultrasonic waves are generated with AD9850 DDS sinusoidal pulse generating module. The sensor data processor uses an Arduino Due microcontroller module by calculating the measured ultrasonic wave travel time difference.

Measurements were made on a $57 \mathrm{~mm}$ diameter pipe with flow rates varied using $25 \%, 50 \%, 75 \%$, and 100\% tap openings. The measurement resulte shows the lowest water debit calculation value of $4.42 \times 10^{-4} \mathrm{~m}^{3} / \mathrm{s}$ at $25 \%$ faucet opening and highest discharge of $2.15 \times 10^{-3} \mathrm{~m}^{3} / \mathrm{s}$ at $100 \%$ faucet opening with the values of coefficient of correlation and coefficient of determination on $25 \%, 50 \%, 75 \%$ and $100 \%$ faucet openings respectively 0.9715 , $0.9669,0.9604$ and 0.9647 and $94.37 \%, 93.49 \%, 92,24 \%$, and $93.07 \%$.

Keywords-ultrasonic flowmeter, travel time, linear regression, coefficient of determination

\section{PENDAHULUAN}

Teknologi memegang peranan yang sangat penting dalam memberikan kemudahan bagi manusia yang dapat dilihat dalam pengukuran dan pemantauan suatu proses. Salah satu 
teknologi yang berkembang adalah tekologi di bidang pengukuran debit air. Teknologi gelombang ultrasonik telah berkembang dan banyak diterapkan pada proses pengukuran. Gelombang ultrasonik adalah suara atau getaran dengan frekuensi tinggi, lebih dari $20,000 \mathrm{~Hz}$ dan kemampuannya yang dapat merambat pada meduim padat, cair, dan gas tanpa merusak profil medium perambatannya.

Penggunaan teknologi pengukuran debit air dalam pipa penerapannya adalah pengukuran debit air pada pipa pengisian tandon. Alat alat pengukur debit air yang bekerja dengan prinsip hall effect. Proses pengukuran yang demikian merusak profil aliran dalam pipa dan akan mempengaruhi kecepatan dan debit aliran yang terukur. Pengukuran dengan gelombang ultrasonik memiliki beberapa keunggulan antara lain pengukuran yang bersifat nonintrusif dan tidak merusak distribusi profil aliran, tidak menyebabkan penurunan tekanan, dan instalasi yang relatif lebih mudah.

Sifat gelombang ultrasonik yang merambat pada medium cair dapat digunakan untuk mengukur kecepatan aliran air yang mengalir melalui pipa silindris [1]. Debit air pada pipa berkorelasi dengan kecepatan aliran air. Nilai debit air yag mengalir pada suatu penampang dapat diperoleh dengan menghitung nilai kecepatan aliran air dan luas penampang saluran yang teraliri air [2]. Berdasarkan latar belakang permasalahan di tersebut dibuat sebuah rumusan masalah yaitu bagaimana merancang alat untuk mengukur debit air pada pipa, dan bagaimana mengukur debit air berdasarkan kecepatannya memanfaatkan sifat gelombang ultrasonik.

\section{METODE PENELITIAN}

\section{$2.1 \quad$ Deskripsi Sistem}

Rancangan sistem untuk penelitian ini ditunjukan agar alat yang dibuat dapat mengukur debit air menggunakan perbedaan kecepatan rambat gelombang ultrasonik menggunakan dua pasang transceiver yang diletakkan pada posisi searah (downstream) dan berlawanan arah aliran air (upstream). Zat cair yang mengalir mempunyai kerapatan zat per volume yang lebih tinggi daripada udara, sehingga untuk mengirim gelombang ultrasonik dari transmitter dan agar gelombang ultrasonik dapat diterima dengan baik oleh receiver maka diperlukan penguatan gelombang ultrasonik. Pada pengujian penguatan gelombang ultrasonik agar dapat melalui aliran air dengan baik, maka diketahui gelombang ultrasonik yang dipancarkan transmitter transduser unltrasonik memerlukan penguatan hingga $8 \mathrm{~V}$. Gambar 1 menunjukkan diagram blok sistem secara keseluruhan.

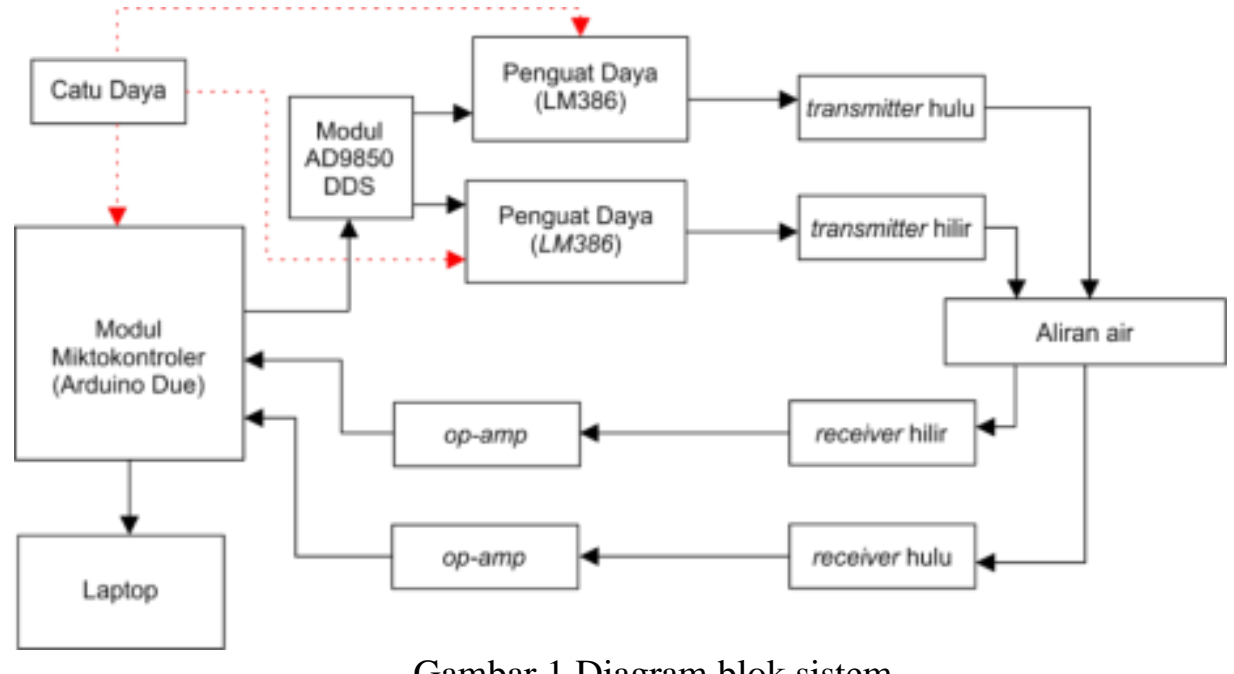

Gambar 1 Diagram blok sistem

Pada penelitian ini telah dibuat suatu perangkat mengukur debit air yang mengalir pada pipa. Elemen utama yang digunakan pada utama ini terdiri dari generator sinyal AD9850 DDS dengan frekuensi kerja $40 \mathrm{KHz}$ yang dibangkitkan dengan pulsa cacah dari modul

IJEIS Vol. 8, No. 1, April 2018: $83-94$ 
mikrokontroler Arduino Due. Transceiver yang tersusun dari empat buah transduser ultrasonik, yaitu dua buah sebagai transduser pengirim dan dua buah sebagai transduser penerima. Transduser-transduser tersebut memiliki frekuensi kerja optimum $40 \mathrm{kHz}$. Perangkat pengolah yang dipakai berupa modul mikrokontroler Arduino Due. Sebuah LED ditempatkan pada papan utama sebagai indikator bagi transmitter saat mengirim gelombang. Perangkat LCD dipasang pada papan utama sebagai penampil hasil pengukuran kecepatan aliran air.

Pipa yang digunakan untuk pengukuran adalah pipa PVC berbentuk silindris yang terbuat dari material padat berbahan polymer dengan kerapatan dan ketebalan dinding sebesar 2 $\mathrm{mm}$ yang menyebabkannya kedap terhadap kebocoran (leaking) saat air mengalir. Pipa tersebut memiliki diameter lingkaran dalam sebesar $57 \mathrm{~mm}$.

Keran dipasang pada ujung pipa untuk memberikan variasi kecepatan aliran air. Data eksperimen diperoleh untuk 10 kali pengambilan data pada masing-masing bukaan keran sebesar $25 \%, 50 \%, 75 \%$ dan $100 \%$. Keran yang digunakan dalam penelitian ini memiliki sudut putaran tuas sejauh $90^{\circ}$. Keran akan terbuka secara penuh apabila tuas diputar hingga mencapai posisi sejajar dengan sumbu aksial pipa dan akan tertutup secara penuh apabila diputar searah jarum jam hingga mencapai posisi tegak lurus terhadap sumbu aksial pipa. Dengan demikian, hubungan persentase bukaan keran dan sudut putaran tuas untuk presentase bukaan 25\%, 50\%, $75 \%$ dan $100 \%$ secara beturut-turut adalah $22,5^{\circ}, 45^{\circ}, 67,5^{\circ}, 90^{\circ}$ terhadap posisi tuas tertutup penuh.

\subsection{Rancangan bagian transmitter}

Rancang bangun bagian transmitter terdiri dari dua bagian identik yang akan mengirimkan gelombang pada posisi hulu dan hilir. Bagian transmitter terdiri dari Arduino Due yang berfungsi mengontrol modul pembangkit pulsa $40 \mathrm{kHz}$ AD9850 DDS, rangkaian penguat daya op-amp LM386 dan transduser ultrasonik $40 \mathrm{kHz}$. Pulsa yang dibangkitkan dari pembangkit gelombang sinus diteruskan ke rangkaian penguat daya untuk dilakukan penguatan tegangan. Keluaran dari rangkaian tersebut diteruskan ke transmitter-transmitter ultrasonik untuk dipancarkan ke aliran air. Gambar 2 merupakan rangkaian skematik pada transmitter.
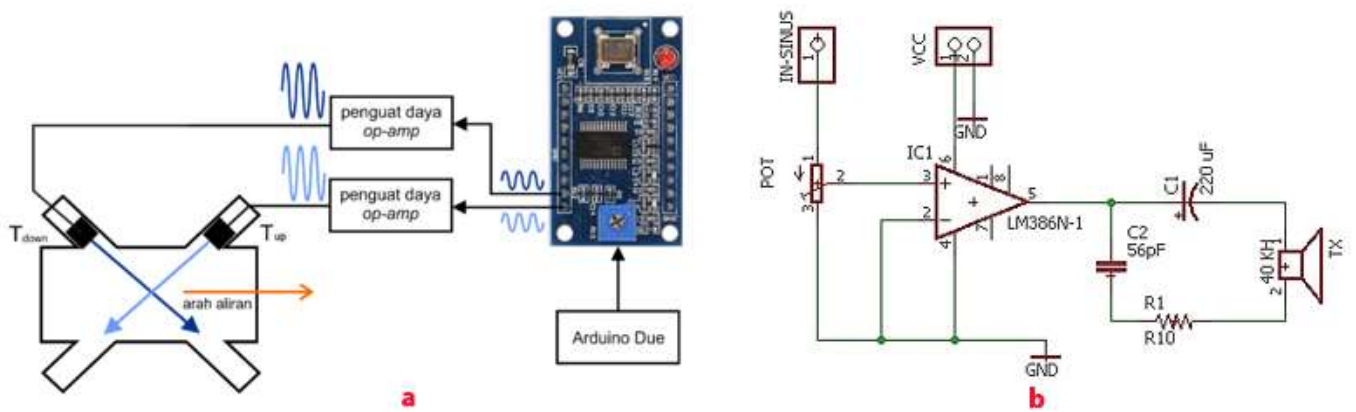

Gambar 2 a. Rancangan bagian transmitter b. Rancangan op-amp transmitter

Tegangan keluaran yang dihasilkan oleh kedua keluaran sinus AD9850 memiliki rentang antara $950 \mathrm{mV}$ hingga $1050 \mathrm{mV}$ [3]. Daya gelombang kemudian ditingkatkan agar dapat menembus aliran air. Air memiliki kerapatan zat yang lebih rapat dibanding kerapatan zat di udara [4], sehingga untuk melalui air yang mengalir, gelombang ultrasonik yang dipancarkan oleh transduser ultrasonik harus melampaui $8 \mathrm{~V}$ untuk dapat merambat pada aliran air secara ideal. Dengan menggunakan op-amp LM386, tegangan gelombang ultrasonik akan dikuatkan hingga mendapat rentang penguatan $8 \mathrm{~V}-16 \mathrm{~V}$. Gambar 3 menunjukkan konfigurasi rangkaian op-amp LM386 yang digunakan pada transmitter.

\subsection{Rancangan bagian receiver}

Bagian receiver berfungsi sebagai penerima gelombang ultrasonik yang telah dipancarkan oleh transmitter. Bagian ini terdiri dari dua transduser ultrasonik pada posisi hulu 
(upstream) dan hilir (downstream) yang masing-masing akan menerima gelombang ultrasonik dari pasangan transmitternya, serta rangkaian penguat op-amp yang berfungsi memperkuat sinyal yang ditangkap oleh transduser. Rancangan bagian receiver ditunjukkan oleh Gambar 4.
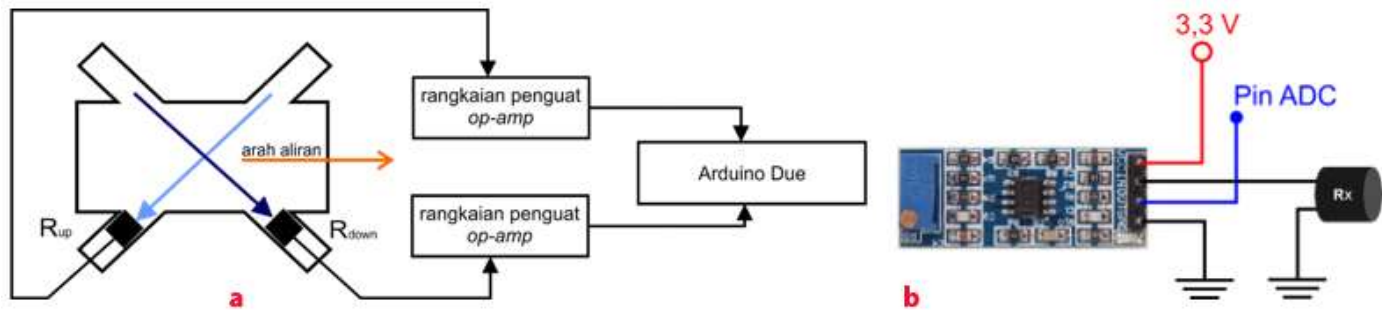

Gambar 4 a. Rancangan bagian receiver $\mathrm{b}$. Rancangan op-amp receiver

Sinyal ultrasonik yang diterima oleh receiver mengalami atenuasi atau pelemahan amplitudo sehingga perlu diperkuat agar dapat terbaca oleh perangkat pengolah [5]. Penguatan sinyal yang diterima oleh receiver pada penelitian ini menggunakan modul op-amp LM358 yang mampu melakukan penguatan optimal sebanyak $100 \mathrm{kali}$. Op-amp jenis ini juga dipilih karena mampu bekerja pada level tegangan minimum yang cukup rendah yakni $3 \mathrm{~V}$ sehingga aplikatif digunakan dengan tegangan referensi 3,3 V yang mampu terbaca tanpa merusak modul Arduino Due. Gambar 5 menunjukkan rancangan penguat receiver dengan modul op-amp LM358.

\subsection{Rancangan transceiver}

Untuk mengukur laju aliran air yang mengalir dalam pipa, dinding luar pipa dilubangi sebagai tempat pemasangan sensor ultrasonik secara wetted type transducer. Transdusertransduser ultrasonik diletakkan tertanam di dalam dinding pipa pada sudut kemiringan $45^{\circ}$ terhadap sumbu aksial pipa pada posisi upstream dan downstream. Jarak antara kedua transmitter dan masing-masing pasangan receiver-nya adalah $10 \mathrm{~cm}$ dengan diameter pipa sebesar $57 \mathrm{~mm}$. Gambar 4.8 menunjukkan rancangan bagian tranceiver yang terpasang pada perangkat pengujian.

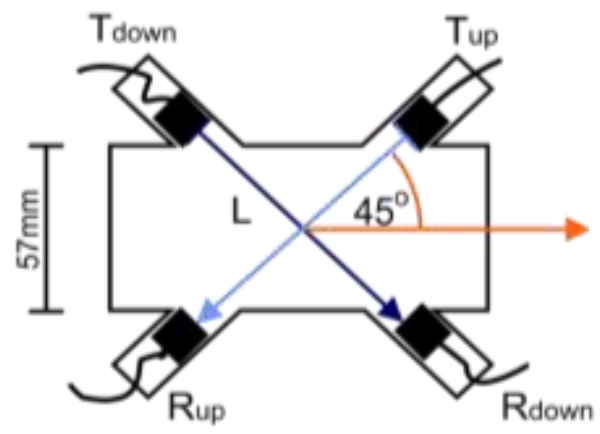

Gambar 6 Rancangan transceiver

\section{$2.4 \quad$ Rancangan perangkat lunak}

Perangkat lunak yang dibuat berfungsi mendukung kinerja sistem dari segi software. Software pemrograman Arduino IDE bertujuan mencuplik waktu tempuh gelombang ultrasonik dari kedua transceiver pada satuan mikrodetik dan mengkalkulasi hasil pengukuran yang diperoleh ke dalam bentuk debit air yang bisa dilihat hasilnya melalui perangkat serial monitor pada Arduino IDE. Gambar 7 menunjukkan flowchart program yang bekerja pada sistem ini. 


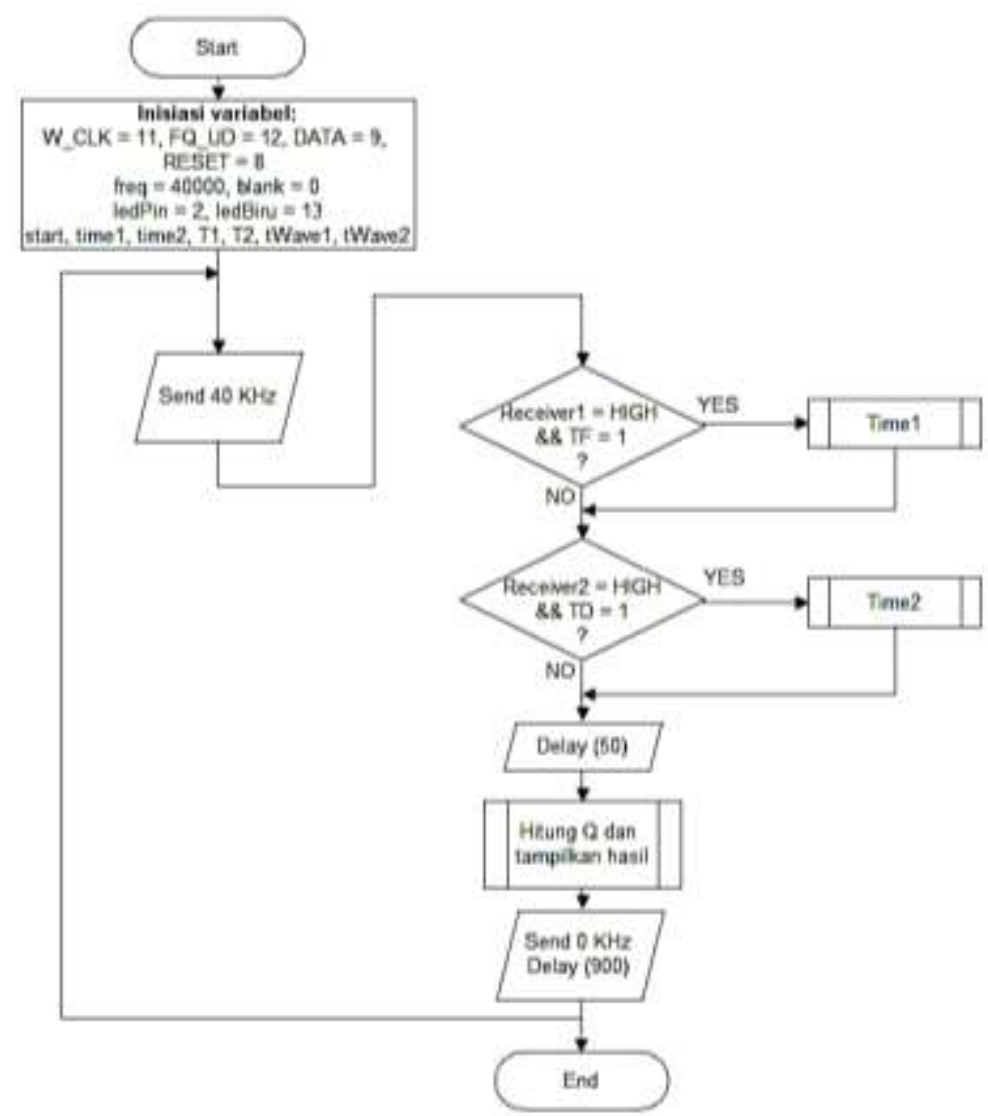

Gambar 7 Flowchart sistem

Program dimulai dengan menginisiasi variabel-varibel dan pin-pin yang digunakan pada sistem. Elemen-elemen yang diinisiasi diantaranya library DDS AD9850, variabel untuk membangkitkan gelombang $40 \mathrm{kHz}$ dari modul AD9850, pin LED, pin ADC sebagai masukan receiver, pin-pin digital yang terhubung ke modul AD9850, variabel penyimpan nilai input dan output, variabel-variabel yang terlibat dengan proses perhitungan debit, serta variabel-variabel yang dipakai dalam sampling waktu dari fungsi micros().

Sistem mengirim gelombang ultrasonik selama sekitar $50 \mathrm{~ms}$ dan berhenti mengirim selama 900 ms.. Waktu awal (start) dicuplik tepat setelah perintah pengiriman diberikan. LED akan menyala selama gelombang terkirim.

Gelombang yang terkirim akan diproses oleh program pengkondisian. Jika receiverl menangkap sinyal ultrasonik, maka waktu tempuh gelombang pada receiver tersebut dicuplik dan disimpan pada sebuah variabel. Jika receiverl menangkap sinyal ultrasonik, maka waktu tempuh gelombang pada receiver tersebut dicuplik dan disimpan pada variabel lainnya. Setelah kedua waktu tempuh tercuplik, sistem melakukan perhitungan debit yang merupakan perkalian luas penampang permukaan yang teraliri aliran dan kecepatan aliran tersebut. Hasil pengukuran kemudian ditampilkan pada perangkat serial monitor dan LCD. Proses ini terus berulang hingga pengguna menonaktifkan perangkat atau menekan tombol restart modul Arduino Due.

\subsection{Rancangan perangkat pengujian}

Perangkat pengujian untuk mengaliri air memiliki panjang $150 \mathrm{~cm}$ dan berdiameter 57 $\mathrm{mm}$ dari wadah pertama sebagai wadah penampung sumber air yang terhubung dengan pipa PVC sepanjang $50 \mathrm{~cm}$ sebelum terhubung dengan tranceiver. Water flow sensor YF DN50 G2 sebagai pembanding. Sebuah keran dipasang pada bagian akhir saluran bertujuan mengatur variasi kecepatan air. Air yang telah mengalir selanjutnya ditampung pada wadah kedua untuk selanjutnya dinaikkan kembali ke wadah pertama menggunakan sebuah pompa AC. Gambar 8 menunjukkan rancangan perangkat pengujian secara umum. 


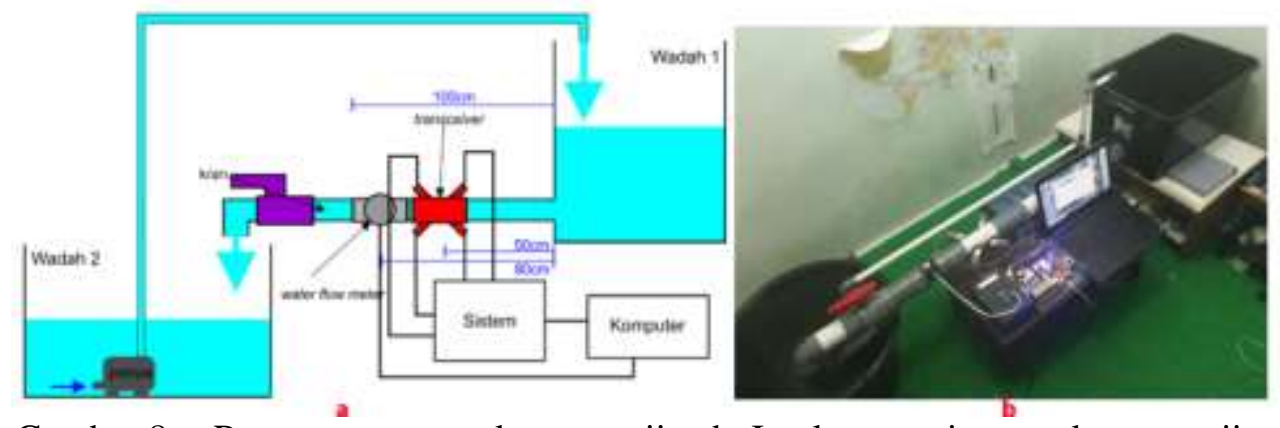

Gambar 8 a. Rancangan perangkat pengujian b. Implementasi perangkat pengujian

\section{HASIL DAN PEMBAHASAN}

\subsection{Hasil pengujian}

Pada hasil pengujian awal, maka akan dibahas hasil pengukuran waktu perambatan gelombang pada kedua receiver secara upstream dan downstream. Menurut Segura (2001 dikutip dalam Prawira 2017), kecepatan gelombang ultrasonik melalui aliran air pada suhu ruangan memiliki kecepatan rambat sebesar $1.000 \mathrm{~m} / \mathrm{s}$ hingga $2000 \mathrm{~m} / \mathrm{s}$, sehingga dengan jarak antar transduser sebesar $10,5 \mathrm{~cm}$ didapat waktu perambatan gelombang ultrasonik pada aliran air sebesar 105 us hingga 525 us. Pengujian ini bertujuan untuk mengetahui apakah sistem berhasil melakukan pengukuran terhadap debit air.

Penelitian ini sebuah alat pembanding standar yang telah tersedia, water flow sensor model YF-DN50 G2, untuk proses kalibrasi. Kalibrasi adalah proses pengecekan dan pengaturan akurasi dari alat ukur dengan cara membandingkannya dengan perangkat standar atau tolak ukur. Kalibrasi diperlukan untuk memastikan bahwa hasil pengukuran yang dilakukan akurat dan konsisten dengan instrumen lainnya [6]. Perangkat yang berperan sebagai kalibrator memiliki resolusi pengukuran $0,0001667 \mathrm{~m} 3 / \mathrm{s}$ hingga $0,0033334 \mathrm{~m} 3 / \mathrm{s}$.

Perhitungan debit memanfaatkan kecepatan aliran air yang terukur dengan menggunakan Persamaan (1) [7].

$$
v=\frac{l}{2 \cdot \cos (\alpha)} \cdot \frac{\Delta t}{\Pi t}
$$

Variabel $v$ adalah kecepatan aliran air yang terukur, $l$ adalah jarak antar transduser pengirim dan transduser penerima, $\alpha$ adalah sudut yang terbentuk oleh posisi transduser terhadap sumbu aksial pipa. Variabel $\Delta \mathrm{t}$ merupakan selisih antara waktu tempuh gelombang secara upstream dan waktu tempuh gelombang secara downstream. Sedangkan Пt merupakan perkalian anatara dua waktu tempuh gelombang pada posisi upstream dan downstream. Nilai kecepatan yang terhitung dalam sistem kemudian di gunakan untuk menghitung debit air. Debit air pada suat penampang berluasan tertentu dapat dihitung menggunakan kecepatan alirannya dengan Persamaan (2) sebagai berikut [8].

$$
\mathrm{Q}=v \times \mathrm{A}
$$

Di mana $\mathrm{Q}$ adalah debit air pada pipa, sedangkan $v$ adalah kecepatan aliran air, dan A adalah luas penampang pipa.

\subsubsection{Contoh pengukuran pada bukaan keran 25\%}

Pengukuran ini dilakukan dengan pengambilan 10 data waktu tempuh gelombang, dan debit air. Hasil pengukuran waktu akan dibandingkan dengan rentang waktu 105 us hingga 525 us sementara debit air yang terukur dibandingkan dengan nilai pengukuran dengan hasil pengukuran water flow sensor YF-DN50 sebagai kalibrator. Tabel 1 menunjukkan hasil salah satu pengukuran waktu tempuh dan debit air pada bukaan keran $25 \%$. 
Tabel 1 Pengujian variasi bukaan keran $25 \%$

\begin{tabular}{|c|c|c|c|c|c|}
\hline Data ke- & $\boldsymbol{t}_{\boldsymbol{u}, \boldsymbol{v}}$ (us) & $\begin{array}{c}\boldsymbol{t}_{\text {down }} \\
(\mathbf{u s})\end{array}$ & $\boldsymbol{v}(\mathbf{m} / \mathbf{s})$ & $\begin{array}{c}\mathbf{Q} \text { Kalibrator } \\
\left(\mathbf{m}^{\mathbf{3}} / \mathbf{s}\right)\end{array}$ & $\begin{array}{c}\mathbf{Q} \text { Terukur } \\
\left(\mathbf{m}^{\mathbf{3}} / \mathbf{s}\right)\end{array}$ \\
\hline 1 & 122 & 111 & 0,1667 & 0,00036674 & 0,00042509 \\
\hline 2 & 124 & 112 & 0,1602 & 0,00040008 & 0,00040842 \\
\hline 3 & 124 & 115 & 0,1569 & 0,00041675 & 0,00040008 \\
\hline 4 & 128 & 115 & 0,1798 & 0,00038341 & 0,00045843 \\
\hline 5 & 134 & 117 & 0,2125 & 0,0003334 & 0,00054178 \\
\hline 6 & 125 & 111 & 0,1928 & 0,00041675 & 0,00049177 \\
\hline 7 & 130 & 117 & 0,1961 & 0,00036674 & 0,0005001 \\
\hline 8 & 132 & 116 & 0,2092 & 0,00048343 & 0,00053344 \\
\hline 9 & 131 & 115 & 0,2027 & 0,00040008 & 0,00051677 \\
\hline 10 & 129 & 116 & 0,183 & 0,00045009 & 0,00046676 \\
\hline Rata-rata & 127,9 & 114,5 & 0,186 & 0,00040175 & 0,00047426 \\
\hline
\end{tabular}

Hasil pengujian terhadap waktu tempuh gelombang menunjukkan kesesuaian terhadap teori. Hasil ini menunjukkan kemampuan sistem untuk memperoleh hasil pengukuran yang sesuai. Waktu tempuh gelombang yang berlawanan arah aliran tercatat lebih besar dibandingkan waktu tempuh gelombang yang searah. Rata-rata waktu tempuh gelombangnya secara berturutturut adalah sebesar 127,9 us dan 114,5 us. Pengukuran dengan alat pembanding dan hasil pengukuran dengan alat yang dibuat menunjukkan hasil dengan nilai rata-rata secara berturutturut sebesar $0,00040175 \mathrm{~m}^{3} / \mathrm{s}$ dan $0,00047426 \mathrm{~m}^{3} / \mathrm{s}$.

\subsection{Pengujian tiap variasi bukaan keran}

Pada penelitian ini, debit air diukur menggunakan alat yang dibuat dan alat pembanding secara bersamaan. Pengujian dilakukan sebanyak 10 kali untuk tiap bukaan keran dengan mengambil 10 data pada tiap kali pengukuran. Hasil pengukuran debit dengan alat pembanding digunakan sebagai acuan dari hasil pengukuran pada penelitian ini yang akan didapatkan penyimpangan dan akurasinya.

Berdasarkan data hasil pengukuran debit air pada pipa, akan didapat perhitungan tingkat akurasi dan presisi pengukuran pada objek uji. Untuk menghitung penyimpangan atau nilai ralat dari suatu pengukuran menggunakan persamaan simpangan baku yang ditunjukkan pada Persamaan (3) berikut [9].

$$
S D=\sqrt{\frac{\sum_{i=1}^{n}\left(x_{i}-x_{r}\right)^{2}}{n}}
$$

Selain itu, dilakukan plotting data hasil pengukuran untuk menentukan karakteristik alat yang dibuat dengan metode analisis regeresi linear sederhana.

Analisis regresi linear menjelaskan hubungan secara linear antara satu variabel independen $(\mathrm{X})$ dengan variabel dependen $(\mathrm{Y})$. Variabel independen pada penelitian ini adalah hasil pengukuran debit dengan menggunakan alat pengukur debit standar yaitu water flow sensor model YF-DN50, sedangkan variabel dependen pada penelitian ini adalah hasil pengukuran debit dari alat flowmeter yang dibuat [10]. Regresi linear dinyatakan dengan Persamaan (4) sebagai berikut:

$$
\begin{gathered}
Y=a+b X \\
a=\frac{\left(\sum Y_{i}\right)\left(\sum X_{i}{ }^{2}\right)-\left(\sum X_{i}\right)\left(X_{i} Y_{i}\right)}{n \sum X_{i}{ }^{2}-\left(\sum X_{i}\right)^{2}} \\
b=\frac{n \sum Y_{U i} Y_{A i}-\left(\sum Y_{U i}\right)\left(\sum Y_{A i}\right)}{n \sum Y_{U i}{ }^{2}-\left(\sum Y_{U i}\right)^{2}}
\end{gathered}
$$

Di mana:

$\mathrm{Y}=$ Variabel dependen (nilai rata-rata pengukuran dengan kalibrator)

$\mathrm{X}=$ Variabel independen (nilai rata-rata pengukuran dengan prototipe)

$\mathrm{Xi}=$ Nilai debit ke-i yang terukur oleh alat prototipe

Yi $=$ Debit ke-i yang terukur oleh kalibrator

$n$ = Banyaknya data

$a \quad=$ Konstanta (nilai Y' apabila $\mathrm{X}=0$ )

$b=$ Koefisien regresi (nilai peningkatan ataupun penurunan) 
Koefisien korelasi adalah ukuran yang dipakai untuk mengetahui derajat hubungan antardua variabel. Persamaan untuk mencari derajat hubungan atau koefisien korelasi mengikuti Persamaan (7) sebagai berikut [12].

$$
r=\frac{n \sum X_{i} Y_{i}-\left(\sum X_{i}\right)\left(\sum Y_{i}\right)}{\sqrt{\left\{n \sum X_{i}^{2}-\left(\sum X_{i}\right)^{2}\right\}\left\{n \sum Y_{i}^{2}-\left(\sum Y_{i}\right)^{2}\right\}}}
$$

Dengan $r$ adalah koefisien korelasi Berdasarkan kriteria besarnya korelasi menurut Guilford [13], yaitu:

- $\quad r<0,20$ : tidak ada korelasi

- $\quad 0,20 \leq \mathrm{r}<0,40$ : korelasi rendah

- $\quad 0,40 \leq \mathrm{r}<0,70$ : korelasi sedang

- $\quad 0,70 \leq \mathrm{r}<0,90$ : korelasi tinggi

- $\quad 0,90 \leq \mathrm{r}<1,00$ : korelasi sangat tinggi

- $\quad r=1,00$ : korelasi sempurna

\subsubsection{Analisa pengukuran bukaan keran $25 \%$}

Bukaan keran 25\% membatasi keluaran air pada pipa dibandingkan dengan besar bukaan lainnya dalam pengujian ini. Dari 10 kali pengujian, diperoleh 10 data nilai rata-rata untuk tiap kali pengukuran yang dilakukan dengan kalibrator dan alat yang dibuat. Nila rata-rata dari hasil pengukuran dengan prototipe pada bukaan keran $25 \%$ sebesar $0,00044218 \mathrm{~m}^{3} / \mathrm{s}$, sementara nilai rata-rata pengukuran dengan kalibrator sebesar $0,00041847 \mathrm{~m}^{3} / \mathrm{s}$.

Data yang telah diperoleh kemudian digunakan untuk mencari simpangan baku guna menentukan seberapa besar nilai ralat, atau simpangannya terhadap nilai rata-rata. Nilai ralat pengukuran debit air pada bukaan keran $25 \%$ didapat dengan menghitung simpangan baku menggunakan Persamaan (3) hingga diperoleh hasil sebesar 0,00007217. sehingga hasil pengukuran debit air pada bukaan keran 50\% yang diperoleh adalah 0,00044218 0,00007217.

Tabel 2 Nilai rata-rata 10 kali percobaan bukaan keran $25 \%$

\begin{tabular}{|c|c|c|}
\hline Percobaan ke- & Q Kalibrator $\left(\mathbf{m}^{3} / \mathbf{s}\right)$ & Q Terukur $\left(\mathbf{m}^{3} / \mathbf{s}\right)$ \\
\hline 1 & 0,00035007 & 0,00034674 \\
\hline 2 & 0,00035174 & 0,00035282 \\
\hline 3 & 0,00049343 & 0,00050343 \\
\hline 4 & 0,00040175 & 0,00043575 \\
\hline 5 & 0,00040341 & 0,00044676 \\
\hline 6 & 0,00044009 & 0,00047259 \\
\hline 7 & 0,00044509 & 0,00047426 \\
\hline 8 & 0,00057345 & 0,00058512 \\
\hline 9 & 0,00037396 & 0,00041592 \\
\hline 10 & 0,00035174 & 0,00038841 \\
\hline Rata-rata & 0,00041847 & 0,00044218 \\
\hline
\end{tabular}

Tabel 2 kemudian diplot sehingga diperoleh persamaan regresi linearnya. Hasil plotting terhadap nilai rata-rata 10 kali pengujian pada bukaan keran 25\% ditunjukkan pada Gambar 9.

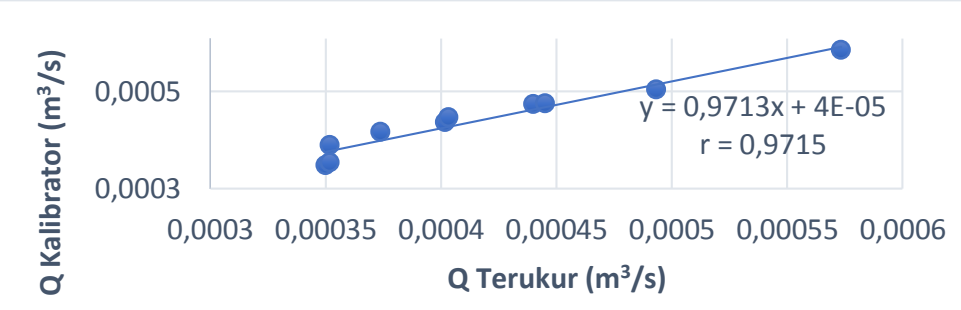

Gambar 9 Grafik regresi linear 10 kali pengukuran pada bukaan keran $25 \%$ 
Berdasarkan grafik tersebut diperoleh persamaan regresi linear yang berlaku untuk pengujian pada bukaan keran $25 \%$ yaitu, $\mathrm{Y}=0,09713 \mathrm{x}+4 \times 10^{-5}$. Nilai koefisien korelasinya 0,9715 sehingga hasil pengukuran pada bukaan keran $25 \%$ menunjukkan korelasi yang sangat tinggi.

\subsubsection{Analisa pengukuran bukaan keran 50\%}

Pengujian pada bukaan keran 50\% dilaksanakan sebanyak 10 kali, tiap kali pengujian diambil 10 data sehingga diperoleh 10 nilai rata-rata untuk tiap kali pengukuran yang dilakukan dengan kalibrator dan alat yang dibuat. Nila rata-rata dari hasil pengukuran dengan prototipe pada bukaan keran $50 \%$ sebesar $0,00082698 \mathrm{~m}^{3} / \mathrm{s}$, sementara nilai rata-rata pengukuran dengan kalibrator sebesar $0,00077891 \mathrm{~m}^{3} / \mathrm{s}$. Tabel 3 menunjukkan data pengukuran pada bukaan keran $50 \%$.

Nilai rata-rata yang telah diperoleh kemudian digunakan untuk mencari simpangan baku guna menentukan seberapa besar nilai ralat terhadap nilai rata-rata. Nilai ralat pengukuran debit air pada bukaan keran 50\% didapat menggunakan Persamaan (3). Simpangan baku mewakili nilai ralat dari pengukuran, sehingga hasil pengukuran debit air pada bukaan keran $50 \%$ yang diperoleh adalah $0,00082698 \pm 0,00006368$.

Tabel 3 Nilai rata-rata 10 kali percobaan bukaan keran 50\%

\begin{tabular}{|c|c|c|}
\hline Percobaan ke- & Q Kalibrator $\left(\mathbf{m}^{3 / \mathbf{s})}\right.$ & Q Terukur $\left(\mathbf{m}^{3 / \mathbf{s}}\right)$ \\
\hline 1 & 0,00072598 & 0,00075598 \\
\hline 2 & 0,00077182 & 0,00082933 \\
\hline 3 & 0,00075598 & 0,00080183 \\
\hline 4 & 0,00089851 & 0,00095769 \\
\hline 5 & 0,00074265 & 0,00078099 \\
\hline 6 & 0,00074682 & 0,00077766 \\
\hline 7 & 0,00072681 & 0,00077932 \\
\hline 8 & 0,00082850 & 0,00085267 \\
\hline 9 & 0,00075682 & 0,00082833 \\
\hline 10 s & 0,00083517 & 0,00090601 \\
\hline Rata-rata & 0,00077891 & 0,00082698 \\
\hline
\end{tabular}

Selanjutnya, Tabel 3 diplot untuk menentukan persamaan regresi linearnya. Hasil plotting terhadap nilai rata-rata 10 kali pengujian pada bukaan keran $50 \%$ ditunjukkan pada Gambar 10.

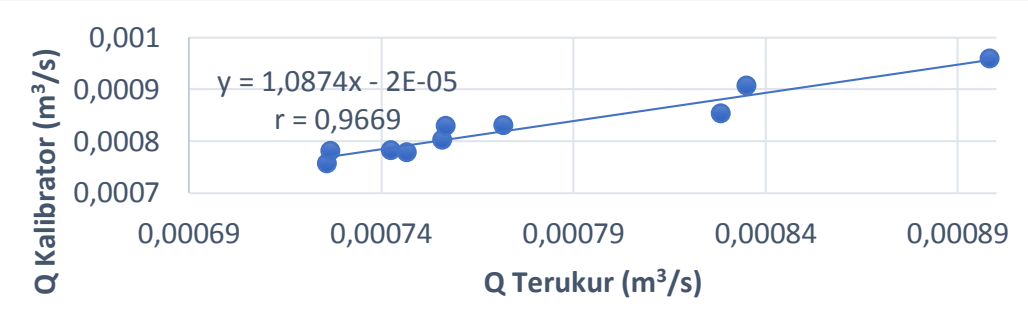

Gambar 10 Grafik regresi linear 10 kali pengukuran bukaan keran 50\%

Berdasarkan grafik tersebut diperoleh persamaan regresi linear yang berlaku untuk pengujian pada bukaan keran $50 \%$ yaitu, $\mathrm{Y}=1,0874 \mathrm{x}+2 \times 10^{-5}$. Nilai koefisien korelasinya 0,9669 sehingga hasil pengukuran pada bukaan keran $50 \%$ menunjukkan korelasi yang sangat tinggi. 


\subsubsection{Analisa pengukuran bukaan keran $75 \%$}

Pengujian pada bukaan keran 75\% dilaksanakan sebanyak 10 kali, tiap kali pengujian diambil 10 data sehingga diperoleh 10 nilai rata-rata untuk tiap kali pengukuran yang dilakukan dengan kalibrator dan alat yang dibuat. Nila rata-rata dari hasil pengukuran dengan alat yang dibuat pada bukaan keran $75 \%$ sebesar $0,00168359 \mathrm{~m}^{3} / \mathrm{s}$, sementara nilai rata-rata pengukuran dengan kalibrator sebesar $0,00167867 \mathrm{~m}^{3} / \mathrm{s}$. Tabel 4 menunjukkan data pengukuran pada bukaan keran $75 \%$.

Tabel 1 Nilai rata-rata 10 kali percobaan bukaan keran $75 \%$

\begin{tabular}{|c|c|c|}
\hline Percobaan ke- & Q Kalibrator $\left(\mathbf{m}^{3} / \mathbf{s}\right)$ & Q Terukur $\left(\mathbf{m}^{3} / \mathbf{s}\right)$ \\
\hline 1 & 0,00158198 & 0,00157948 \\
\hline 2 & 0,00171034 & 0,00171201 \\
\hline 3 & 0,00181536 & 0,00176785 \\
\hline 4 & 0,0015003 & 0,00154948 \\
\hline 5 & 0,00180036 & 0,00176452 \\
\hline 6 & 0,00171868 & 0,00175452 \\
\hline 7 & 0,00160699 & 0,00161699 \\
\hline 8 & 0,00169034 & 0,00168284 \\
\hline 9 & 0,00171701 & 0,00174618 \\
\hline 10 & 0,00164533 & 0,001662 \\
\hline Rata-rata & 0,00167867 & 0,00168359 \\
\hline
\end{tabular}

Nilai rata-rata yang telah diperoleh selanjutnya digunakan untuk mencari simpangan baku guna menentukan seberapa besar nilai ralat terhadap nilai rata-rata. Nilai ralat pengukuran debit air pada bukaan keran $75 \%$ didapat menggunakan Persamaan (3). Simpangan baku mewakili nilai ralat dari pengukuran, sehingga hasil pengukuran debit air pada bukaan keran $75 \%$ yang diperoleh adalah $0,00168359 \pm 0,00007968$.

Tabel 4 kemudian diplot untuk menentukan persamaan regresi linearnya. Hasil plotting terhadap nilai rata-rata 10 kali pengujian pada bukaan keran 75\% ditunjukkan pada Gambar 11 .

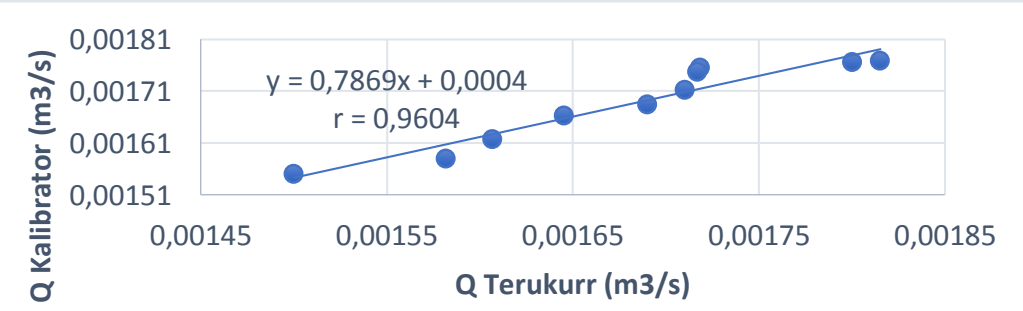

Gambar 11 Grafik regresi linear 10 kali pengukuran bukaan keran $75 \%$

Berdasarkan grafik tersebut diperoleh persamaan regresi linear yang berlaku untuk pengujian pada bukaan keran $50 \%$ yaitu, $\mathrm{Y}=0,7869 \mathrm{x}+0,0004$. Nilai koefisien korelasinya 0,9604, sehingga hasil pengukuran pada bukaan keran $75 \%$ menunjukkan korelasi yang sangat tinggi.

\subsubsection{Analisa pengukuran bukaan keran 100\%}

Pengujian pada bukaan keran 100\% dilaksanakan sebanyak 10 kali, tiap kali pengujian diambil 10 data sehingga diperoleh 10 nilai rata-rata untuk tiap kali pengukuran yang dilakukan dengan kalibrator dan alat yang dibuat. Nila rata-rata dari hasil pengukuran dengan alat yang dibuat pada bukaan keran $100 \%$ sebesar $0,00215353 \mathrm{~m}^{3} / \mathrm{s}$, sementara nilai rata-rata pengukuran dengan kalibrator sebesar $0,00212059 \mathrm{~m}^{3} / \mathrm{s}$. Tabel 5 menunjukkan data pengukuran pada bukaan keran $100 \%$. 
Nilai rata-rata yang telah diperoleh selanjutnya digunakan untuk mencari simpangan baku guna menentukan seberapa besar nilai ralat terhadap nilai rata-rata. Nilai ralat pengukuran debit air pada bukaan keran 100\% didapat menggunakan Persamaan (3). Simpangan baku mewakili nilai ralat dari pengukuran, sehingga hasil pengukuran debit air pada bukaan keran $100 \%$ yang diperoleh adalah $0,00215353 \pm 0,00006302$.

Tabel 5 Nilai rata-rata 10 kali percobaan bukaan keran $100 \%$

\begin{tabular}{|c|c|c|}
\hline Percobaan ke- & Q Kalibrator $\left(\mathbf{m}^{3} / \mathbf{s}\right)$ & Q Terukur $\left(\mathbf{m}^{3 / \mathbf{s}}\right)$ \\
\hline 1 & 0,00202374 & 0,00202624 \\
\hline 2 & 0,00212209 & 0,00216127 \\
\hline 3 & 0,00207208 & 0,00211459 \\
\hline 4 & 0,00206708 & 0,00210459 \\
\hline 5 & 0,00214543 & 0,00218460 \\
\hline 6 & 0,00210042 & 0,00214726 \\
\hline 7 & 0,00215376 & 0,00217377 \\
\hline 8 & 0,00217043 & 0,00218044 \\
\hline 9 & 0,00217877 & 0,00222545 \\
\hline 10 & 0,00217210 & 0,00221711 \\
\hline Rata-rata & 0,00212059 & 0,00215353 \\
\hline
\end{tabular}

Tabel 5 kemudian diplot untuk menentukan persamaan regresi linearnya. Hasil plotting terhadap nilai rata-rata 10 kali pengujian pada bukaan keran $100 \%$ ditunjukkan pada Gambar 12.

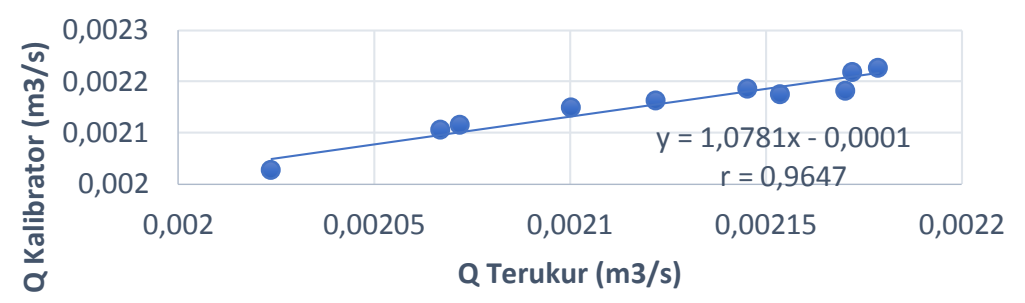

Gambar 12 Grafik regresi linear 10 kali pengukuran bukaan keran 100\%

Berdasarkan grafik tersebut diperoleh persamaan regresi linear yang berlaku untuk pengujian pada bukaan keran $50 \%$ yaitu, $\mathrm{Y}=1,0781 \mathrm{x}-1 \times 10^{-4}$. Nilai koefisien korelasinya 0,9647 sehingga hasil pengukuran pada bukaan keran $100 \%$ menunjukkan korelasi yang sangat tinggi.

\section{KESIMPULAN}

Berdasarkan penjelasan pada bagian hasil dan pembahasan, diperoleh kesimpulan atanra lain: Pertama, telah berhasil membuat alat berupa flowmeter ultasonik untuk mengukur debit air berdasarkan kecepatannya memanfaatkan sifat gelombang ultrasonik. Kedua, proses pengukuran berhasil mengukur debit air pada variasi bukaan keran $25 \%, 50 \%, 75 \%$, dan $100 \%$. Ketiga, hasil pengujian pada sistem yang telah dibuat memiliki tingkat akurasi dan tingkat presisi yang baik, dengan rincian; hasil pengujian pengambilan data 10 kali pada bukaan keran $25 \%$ menunjukan nilai sebesar $0,00044218 \pm 0,00007217 \mathrm{~m}^{3} / \mathrm{s}$; hasil pengujian pengambilan data 10 kali pada bukaan keran $50 \%$ menunjukan nilai sebesar $0,00082698 \pm 0,00006368 \mathrm{~m}^{3} / \mathrm{s}$; hasil pengujian pengambilan data 10 kali pada bukaan keran $75 \%$ menunjukan nilai sebesar $0,00168359 \pm 0,00007968 \mathrm{~m}^{3} / \mathrm{s}$; dan hasil pengujian pengambilan data 10 kali pada bukaan keran $100 \%$ menunjukan nilai sebesar $0,00215353 \pm 0,00006302 \mathrm{~m}^{3} / \mathrm{s}$. Selain itu, hasil 
perhitungan terhadap koefisien korelasi pada pengukuran debit keempat bukaan keran menunjukkan korelasi sangat tinggi.

\section{SARAN}

Pada penelitian ini masih terdapat beberapa hal yang perlu disempurnakan. Saran-saran yang berikut dapat digunakan untuk menyempurnakan penelitian selanjutnya. Pertama, perlu lebih teliti dan pemasangan transduser ultrasonik agar penerimaan gelombang yang diperoleh lebih optimal. Kedua, perlu adanya penggunaan multiplekser pada bagian transceiver sebagai saran pengembangan untuk mengurangi penggunaan transuduser ultrasonik.

\section{DAFTAR PUSTAKA}

[1] A. Bailleu, "Ultrasonic Transducer Positioning System for Clamp-on Flowmeter Applications," IEEE Instrum. Meas. Soc., 2016 [Online]. http://ieeexplore.ieee.org.ezproxy.ugm.ac.id/document/7479831. [Accessed: 5-Des-2017]

[2] P. Simartama, 2014, "Perancangan Alat Pengukur Kecepatan \& Debit Suatu Aliran Cairan Berbasis Mikrokontroler," Skripsi, Fakultas Matematika dan Ilmu Pengetahuan Alam, Universitas Sumatera Utara, Medan.

[3] S. Swasoko and A. Rouf, "Rancang Bangun Pembangkit Pulsa Tiga Sensor Ultrasonik Untuk Pendeteksi Kecacatan Beton Berbasis Mikrokontroler," Indones. J. Electron. Instrum. Syst, vol. 7, no. 2, pp. 197-208, 2017 [Online]. Available at: https://jurnal.ugm.ac.id/ijeis/article/view/24276. [Accessed: 20-Des-2017]

[4] B. Prawira, 2017, "Perancangan Alat Pengukur Massa Jenis Zat Cair dengan Gelombang Ultrasonik," Skripsi, Fakultas Matematika dan Ilmu Pengetahuan Alam, Universitas Gadjah Mada, Yogyakarta.

[5] S. Aji, 2016, "Pengaruh Cacat Beton Terhadap Kekuatan Sinyal Pantul Gelombang Ultrasonik,", Skripsi, Fakultas Matematika dan Ilmu Pengetahuan Alam, Universitas Gadjah Mada, Yogyakarta.

[6] A. Morris, Measurement and Instrumentation Principles, 3rd ed. Oxford: ButterworthHeinemann, 2001.

[7] A. Bailleu, "Sensors \& Transducers Sound Propagation and Signal Quality of Ultrasonic Sensors in Dependency on the Distance of the Transducers," Sensors Appl. Symp. (SAS), 2016 IEEE, vol. 201, no. 6, pp. 9-16, 2016.

[8] A. Finawan, "Pengukuran Debit Air Berbasis Mikrokontroler AT89S51," J. Litek, vol. 8, pp. 28-31, 2011.

[9] K. G. Suastika, M. Nawir, and P. Yunus, "Sensor Ultrasonik Sebagai Alat Pengukur Aliran Udara dalam Pipa,” J. Pendidik. Fis. Indones., vol. 9, pp. 163-172, 2013.

[10] W. Budiaji and Y. L. A. Salampessy, "Pendugaan Standar Deviasi untuk Sampel Kecil dalam Penelitian Petanian," Jurnal Ilmu Pertan. dan Perikan., vol. 1, no. 1, pp. 37-42, 2012. 